\title{
Genotype patterns and prevalence of human papilloma virus in non-vaccinated women in Zunyi, China
}

Yu Zhao, MM, Kaifeng Wu, MD, Huabo Tong, MB, Yan Liu, MB, He Zha, MD, Huan Yue, MM, Jingzhi Zhang, MB, Xiaoyun Liu, MD.

\section{ABSTRACT}

الأهداف : تحديد أنماط وانتشار الأنماط الجينية لفيروس الورم الحليمي

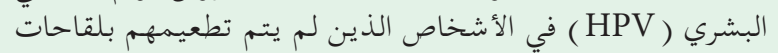

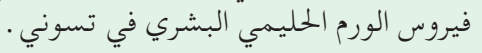

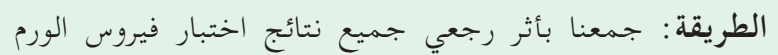

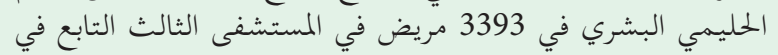

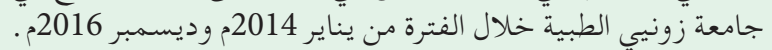

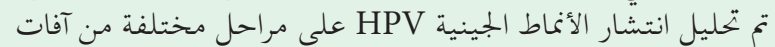

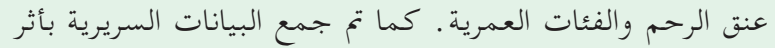

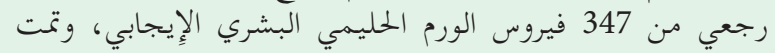

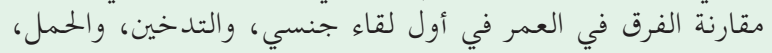

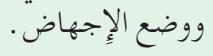

النتائج: أصيب مجموعة 511 مريض بفيروس الورم الحليمي البشري ، بمعدل إِيجابي إِجمالي 15.1\% (511/3,393) .

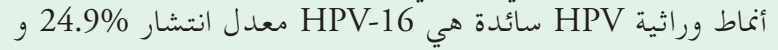

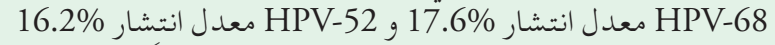

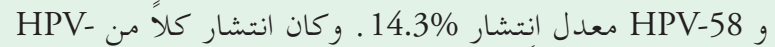

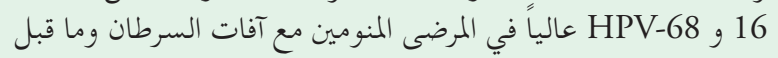

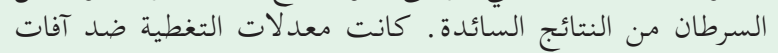

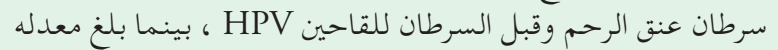

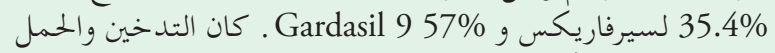

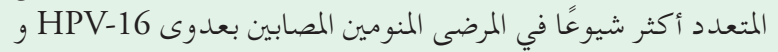
HPV-68

الخاتمة : HPV-68 و Hما النمطان الأكثر انتشاراً وخطورة

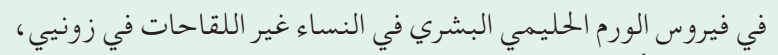

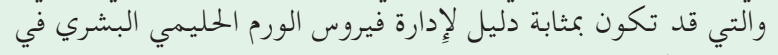
زونيي، الصين.

Objectives: To determine the patterns and prevalence of human papilloma virus (HPV) genotypes in people who are not vaccinated with HPV vaccines in Zunyi.

Methods: We retrospectively collected all HPV testing results in 3,393 patients at the Third Affiliated Hospital in Zunyi Medical University, Zunyi, China between January 2014 and December 2016. The prevalence of HPV genotypes based on different stages of cervical lesions and age groups was analyzed. The clinical data of $347 \mathrm{HPV}$-positive inpatients were also retrospectively collected, and difference in the age at first sexual encounter, smoking, pregnancy, and abortion status were compared.

Results: A total of 511 patients were infected with HPVs, with an overall positive rate of $15.1 \%(511 / 3,393)$. The most prevalent HPV genotypes were HPV-16 with prevalence rates of $24.9 \%$, HPV-68 with $17.6 \%$, HPV-52 with $16.2 \%$, and $\mathrm{HPV}-58$ with $14.3 \%$. High prevalence of HPV-16 and HPV-68 in inpatients with pre-cancer and cancer lesions was one of the predominant findings. The coverage rates against cervical pre-cancer and cancer lesions for the $2 \mathrm{HPV}$ vaccines, Cervarix was $35.4 \%$ and Gardasil 9 was 57\%. Smoking and multiple pregnancy were more common in inpatients with HPV-16 and HPV-68 infection than those with other genotypes.

Conclusions: Human papilloma virus-16 and HPV-68 are the 2 most prevalent and high-risk HPV genotypes in non-vaccinated women in Zunyi, which may serve as a guide for HPV management in Zunyi, China.

Saudi Med J 2018; Vol. 39 (6): 572-578

doi:10.15537/smj.2018.6.22132

From the Department of Laboratory Medicine (Zhao, Wu, Tong, Liu, Zha, Yue, Zhang), and from the Department of Gynaecology and Obstetrics (Liu), The Third Affiliated Hospital of Zunyi Medical University, Zunyi, China.

Received 22nd January 2018. Accepted 17th May 2018.

Address correspondence and reprint request to: Dr. Kaifeng Wu, Department of Laboratory Medicine, The Third Affliated Hospital of Zunyi Medical University (The First People's Hospital of Zunyi), Zunyi, China.E-mail:kiphoonwu@126.com

ORCID ID: orcid.org/0000-0002-8340-8866 
C Cervical cancer (CC) is a common malignancy in women, with a continuously increasing incidence. ${ }^{1}$ In 2012, approximately 445,000 new cases were diagnosed, and $>270,000$ women died of CC every year. ${ }^{2}$ Cervical cancer has been recognized as a human papillomavirus (HPV)-related disease. Pre-cancer lesions, including cervical atypical hyperplasia, cervical intraepithelial neoplasia (CIN), and in situ cervical carcinoma, are also HPV-related events and are commonly caused by persistent infections with HPVs. Human papillomavirus is a spherical, double-stranded, and closed-loop DNA virus belonging to the genus A of the vacuolar virus of papilloma, with a genome length of 7.2-8.0 kb. More than 200 genotypes have been reported; among them, $>30$ kinds were associated with genital tract disease, and more than 20 kinds were tumor-related. Without fully considering the genetic background of the population, HPV has been grouped into high-risk HPV (HR-HPV) and low-risk HPV (LR-HPV) genotypes. Human papillomavirus-16 and HPV-18 were recognized as the most common HR-HPV genotypes worldwide, which were responsible for approximately $70 \%$ of CC cases. ${ }^{3}$ The following prevalent HPVs were genotypes HPV-31, HPV-45, and HPV-52, which collectively accounted for the remaining $30 \%$ of cases. ${ }^{3,4}$ In China, HPV-16, HPV-18, HPV-52, and HPV-58 were the most common genotypes in women; ${ }^{5}$ however, the genotypes and prevalence of HPV may vary geographically. ${ }^{6}$ So far, the epidemiologic data on HPV prevalence have not been reported in Zunyi, China. In addition, despite the availability of prophylactic HPV vaccine, Cervarix, in China since 2016, ${ }^{7}$ residents in Zunyi doubted its effectiveness and significance. This situation and people's concerns highlight the importance to estimate the genotypes and prevalence of HPV in this region. Therefore, we collected all HPV testing data in patients who visited the Third Affiliated Hospital in Zunyi Medical University, Zunyi, China between January 2014 and December 2016.

Disclosure. Authors have no conflict of interests, and the work was not supported or funded by any drug company. This study was supported by research grants from Innovation talent team of science and technology jointly provided by Zunyi City and the first people's hospital of Zunyi (No. 17, 2015), the special fund for science and technology cooperation between Guizhou Province and Zunyi City (No. 38, 2015), and Projects of the National Natural Science Foundation of China (81760475).
The genotypes and prevalence of HPVs were analyzed, and the difference in prevalence among inpatients with HPV carrier and cervical pre-cancer and cancer lesions were compared. Coverage rates for HPV vaccines, Cervarix and Gardasil 9, were determined in inpatients with cervical pre-cancer and cancer lesions. The results presented here provide baseline information on HPV prevalence and genotype patterns, which will serve as a guide in using these vaccines in this region

Methods. All procedures performed in this study involving human participants were approved by the Ethics Committee of the Third Affiliated Hospital in Zunyi Medical University (Reference number: 2017-10) and in accordance with the 1964 Helsinki Declaration on ethical standards. All patients signed a written consent regarding the use of their samples and basic information when they were hospitalized.

Population and specimen collection. A total of 3,393 women, including 2,441 outpatients and 952 inpatients, were tested for HPV at the Third Affiliated Hospital in Zunyi Medical University (a teaching hospital with 2,500 beds), from January 2014 to December 2016, and the results were retrospectively analyzed. A total of 550 women who visited the hospital for normal physical examination and voluntarily chose to have HPV testing were grouped as outpatients. Others were outpatients suspected with cervical ectopic columnar epithelium and were screened for HPV. Specimen collection and shipping were strictly performed according to the instructions provided by the manufacturer of HPV analysis kits and the Ministry of Health in China. Briefly, cervical secretions were collected by trained doctors and stored at $2-8^{\circ} \mathrm{C}$ before DNA extraction no more than 3 days. Cervical secretion was the only source of sample for laboratory use.

Human papillomavirus-DNA extraction and real-time polymerase chain reaction (rtPCR). Sample preparation was carried out in biosafety level 2 facilities. Viral DNA was extracted from cervical secretion samples with the help of a commercial kit (provided by Shanghai ZJ Bio-Tech Co., Ltd., Shanghai, China). The HPV genotyping real-time PCR kit (Shanghai ZJ Bio-Tech Co., Ltd., Shanghai, China) was used to detect HPV genotypes, including HPV-16, HPV-18, HPV-31, HPV-33, HPV-35, HPV-39, HPV-45, HPV-51, HPV-52, HPV-56, HPV-58, HPV-59, and HPV-68. The amplification was performed using SLAN qPCR analyzer (Shanghai Hongshi Medical Technology Co.,LTD). All procedures including DNA extraction, PCR amplification, and result analysis were performed according to the manufacturer's 
instructions. The pre-cancer and cancer lesions were diagnosed based on histological examination. The data regarding the grading of CIN 1-3 and invasive CC were diagnosed according to the World Health Organization classification guidelines. ${ }^{8}$ Clinical data were obtained from the medical record system with the permission of the Ethics Committee at the Third Affiliated Hospital in Zunyi Medical University.

Statistical analyses. All categorical variables were compared using Chi-square tests and were reported as frequencies and percentages. The quantitative data were analyzed using Kruskal-Wallis $\mathrm{H}$ test. All data analyses were compared using SPSS version 19.0 (SPSS, Chicago, IL, USA). All statistical tests were 2-sided, and $p$-value of $<0.05$ was considered statistically significant.

Results. A total of 3,393 patients were tested for HPV infection in Zunyi City, Guizhou Province, China, from January 2014 to December 2016. Among them, $15.1 \%(511 / 3,393)$ were infected with HPVs, and the remaining 2,882 cases were negative for HPV infection. Among the HPV-positive cases, 67.9\% (347/511) were inpatients, and $22.79 \%$ (79/347) of them were diagnosed with CIN grades 1 to 3 or CC. As shown in Figure 1, both the number of cases and positive rates of HPV infection in Zunyi City are continuously increasing since 2014.

Overall genotype and distribution of HPVs in Zunyi. Figure 2 shows the number and percentage of all $13 \mathrm{HPV}$ genotypes in $511 \mathrm{HPV}$-positive cases.

Table 1 shows the genotype distribution and number of cases with HPV infection in the 347 inpatient HPVpositive women. Among all the identified genotypes, HPV-16, HPV-52, and HPV-68 were the 3 most prevalent genotypes, followed by HPV-58, HPV-59, HPV-18, HPV-56, HPV-51, HPV-39, HPV-35, HPV-33, HPV-31, and HPV-45. All patients with CC were also found to be simultaneously infected with multiple HPV genotypes (7/7), and HPV-16 and HPV-68 were simultaneously found in 5 out of 7 patients with CC. To compare the prevalence of HPV between carriers and patients with cervical lesions, we combined the patients with CIN 1-3 or CC into one group. Human papillomavirus-16 ( $p<0.001)$, HPV-68 $(p=0.006)$, and multiple-type infection $(p<0.001)$ were significantly more prevalent in inpatients with cervical lesions than HPV carriers, suggesting that infection with these genotypes is a high-risk factor for the development of pre-cancer lesions or CC.

A total of $13 \mathrm{HPV}$ genotypes, including HPV-16, HPV-18, HPV-51, HPV-33, HPV-39, HPV-68,

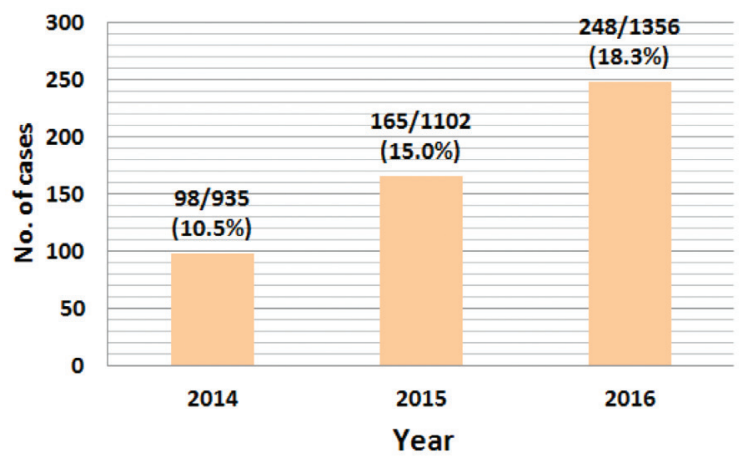

Figure 1 - Annual number and percentage of HPV-positive cases in Zunyi City, China. Figures in brackets refer to percentage of cases relative to the total number of tests in the corresponding years.

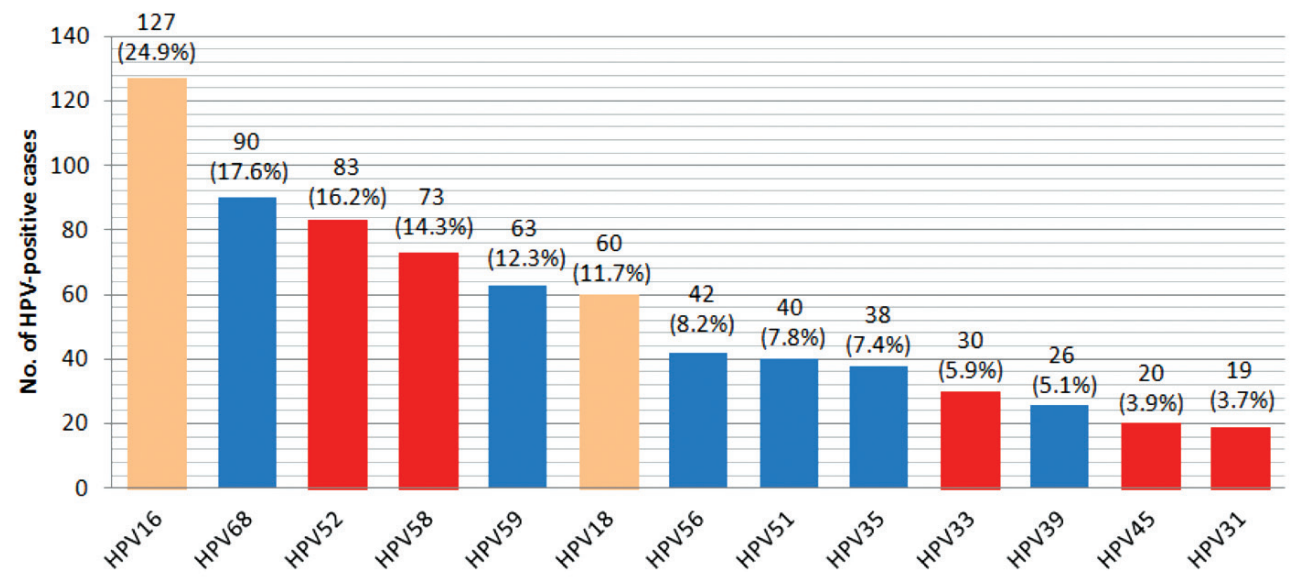

Figure 2 - The prevalence of Human papilloma virus (HPV) genotypes in Zunyi, China, from January 2014 to December 2016. 
HPV-35, HPV-31, HPV-45, HPV-56, HPV-58, HPV-59, and HPV-52, were determined using real-time PCR. The number and percentage of each HPV genotype were calculated.

Coverage estimation of HPV vaccines. Since the introduction of HPV vaccine, Cervarix, in China in 2016, we were interested in its coverage against HPV infection in inpatients with cervical pre-cancer and cancer lesions in Zunyi City. ${ }^{7}$ We found that only $35.4 \%$ of HPV genotypes were covered by Cervarix. Since genotypes 6 and 11 were not analyzed in this study, the coverage estimation for Gardasil would be biased and was therefore not calculated. Gardasil 9 is another protective $\mathrm{HPV}$ vaccine that covers most HPV genotypes, including HPV-6, HPV-11, HPV-16, HPV-18, HPV-31, HPV-33, HPV-45, HPV-52, HPV-58, and its coverage was therefore estimated. This vaccine could cover $57 \%$ of the genotypes found in inpatients with cervical pre-cancer and cancer lesions in Zunyi City.

Overall genotype and distribution of HPVs in Zunyi. Table 2 shows the distribution of HPV genotypes in single- and multiple-type infections in 347 inpatient HPV-positive women. The 4 most common genotypes in multiple-type infection were HPV-68, HPV-16, HPV-52, and HPV-18. In addition, HPV-68, HPV-16, HPV-52, HPV-18, HPV-59, HPV-51, HPV-33, HPV-39, and HPV-45 were significantly more prevalent in inpatients with multiple-type HPV infection than those with single-type HPV infection.
Table 3 shows the prevalence of HPVs in inpatients grouped based on ages. ${ }^{6}$ The prevalence of HPV-18 was found to be significantly higher in the age group of $<35$ years than the other 2 age groups $(p<0.001)$, whereas HPV-59 was more prevalent in patients aged $35-46$ years $(p=0.03)$. Compared to younger age groups, HPV-56 was more prevalent in participants aged $>46$ years. Differences in the prevalence of other HPV genotypes were insignificant among different age groups.

Table 2 - Distribution of human papilloma virus (HPV) genotypes in inpatients with single- and multiple-type infections.

\begin{tabular}{lcccccrc}
\hline Genotypes & \multicolumn{3}{c}{$\begin{array}{c}\text { Multiple-type } \\
\text { infection }\end{array}$} & \multicolumn{6}{c}{ Single-type infection } & P-value $^{\text {a }}$ \\
& $\begin{array}{c}\text { Total } \\
\text { cases }\end{array}$ & $\mathbf{n}$ & $(\%)$ & $\begin{array}{l}\text { Total } \\
\text { cases }\end{array}$ & $\mathbf{n}$ & $(\%)$ & \\
\hline HPV-68 & 85 & 40 & $(47.1)$ & 262 & 17 & $(6.5)$ & $<0.001$ \\
HPV-16 & 85 & 38 & $(44.7)$ & 262 & 48 & $(18.3)$ & $<0.001$ \\
HPV-52 & 85 & 21 & $(24.7)$ & 262 & 38 & $(14.5)$ & 0.03 \\
HPV-18 & 85 & 17 & $(20.0)$ & 262 & 23 & $(8.8)$ & 0.005 \\
HPV-59 & 85 & 16 & $(18.8)$ & 262 & 25 & $(9.5)$ & 0.02 \\
HPV-58 & 85 & 15 & $(17.6)$ & 262 & 30 & $(11.5)$ & 0.139 \\
HPV-51 & 85 & 10 & $(11.8)$ & 262 & 12 & $(4.6)$ & 0.018 \\
HPV-33 & 85 & 10 & $(11.8)$ & 262 & 10 & $(3.8)$ & 0.006 \\
HPV-56 & 85 & 10 & $(11.8)$ & 262 & 20 & $(7.6)$ & 0.24 \\
HPV-39 & 85 & 9 & $(10.6)$ & 262 & 12 & $(4.6)$ & 0.044 \\
HPV-35 & 85 & 8 & $(9.4)$ & 262 & 13 & $(5.0)$ & 0.135 \\
HPV-45 & 85 & 8 & $(9.4)$ & 262 & 4 & $(1.5)$ & $<0.001$ \\
HPV-31 & 85 & 4 & $(4.7)$ & 262 & 10 & $(3.8)$ & 0.717 \\
\hline
\end{tabular}

${ }^{a} p$-values for the prevalence differences between the 2 groups were determined with the Chi-square test.

Table 1 - Distribution of human papilloma virus (HPV) genotypes in inpatients according to histopathology.

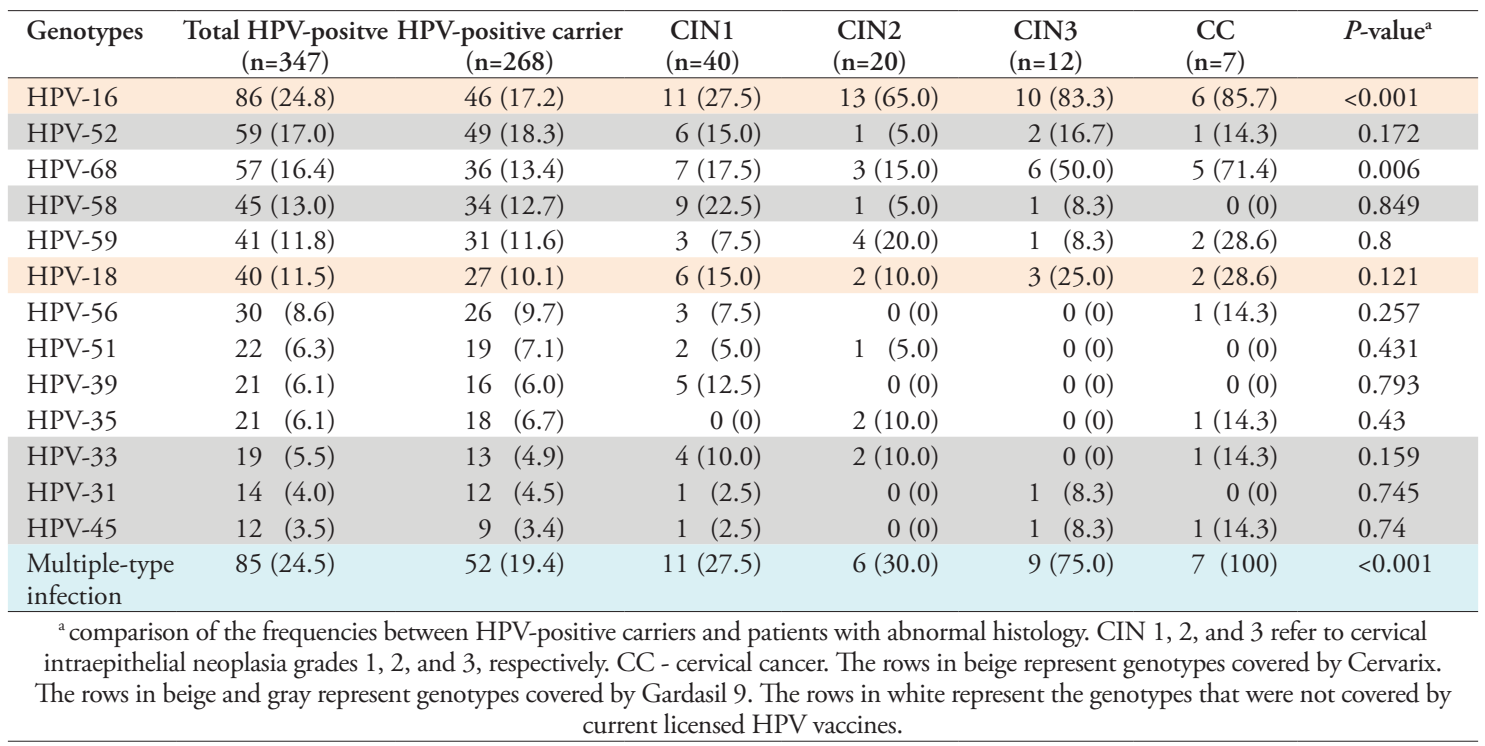


The median age of all study participants was 39 (range, 15-86) years, and the median age for HPV+ population was 41 (range, 17-78) years. Table 4 shows the demographic and clinical features of inpatients infected with HPV-16, HPV-18, HPV-52, HPV-68, and other genotypes. According to our data, infection with HPV18 was preferentially detected in persons younger than 35 years whereas HPV-16 infection rates increased with age (Table $3 \&$ Table 4, median age of infection, 32.5 versus 43 years, $p=0.004)$. Compared to other HPVs, HPV-16, and HPV-68 were more prevalent in participants who smoke $(p=0.006$ and $p=0.029)$. In addition, most of the inpatients infected with HPV-16 and HPV-68 had higher number of pregnancies compared to other participants $(p<0.05)$. Differences in the age during the first sexual encounter and abortion were insignificant among groups.

Discussion. Human papilloma virus infection remains a common public health problem in China affecting a large number of women. ${ }^{9}$ Several studies have reported the prevalence of HPV genotypes in

Table 3 - The number of cases and HPV prevalence in inpatients according to ages.

\begin{tabular}{|c|c|c|c|c|c|}
\hline \multirow{2}{*}{ Genotype } & \multicolumn{4}{|c|}{ HPV-positive cases in inpatients $(\mathrm{N}=347)$} & \multirow[t]{2}{*}{$P$-value ${ }^{\mathrm{a}}$} \\
\hline & $\begin{array}{l}\text { Total } \\
\text { cases }\end{array}$ & $\begin{array}{c}<35 \text { years } \\
(\mathrm{n}=119)\end{array}$ & $\begin{array}{c}35-46 \text { years } \\
(n=115)\end{array}$ & $\begin{array}{c}>46 \text { years } \\
(\mathrm{n}=113)\end{array}$ & \\
\hline HPV-16 & $86(24.8)$ & $22(18.5)$ & $30(26.1)$ & $34(30.1)$ & 0.103 \\
\hline HPV-52 & $59(17.0)$ & $18(15.1)$ & $24(20.9)$ & $17(15.0)$ & 0.329 \\
\hline HPV-68 & $57(16.4)$ & $19(16.0)$ & $18(15.7)$ & $8(8.8)$ & 0.179 \\
\hline HPV-58 & $45(13.0)$ & $18(15.1)$ & $9(7.8)$ & $18(15.9)$ & 0.152 \\
\hline HPV-59 & $41(11.8)$ & $8(6.7)$ & $20(17.4)$ & $13(11.5)$ & 0.03 \\
\hline HPV-18 & $40(11.5)$ & $24(20.2)$ & $5(4.3)$ & $11 \quad(9.7)$ & $<0.001$ \\
\hline HPV-56 & $30 \quad(8.6)$ & $6(5.0)$ & $8 \quad(7.0)$ & $16(14.2)$ & 0.035 \\
\hline HPV-51 & $22(6.3)$ & $6 \quad(5.0)$ & $4 \quad(3.5)$ & $12(10.6)$ & 0.07 \\
\hline HPV-39 & $21 \quad(6.1)$ & $10(8.4)$ & $4(3.5)$ & $7 \quad(6.2)$ & 0.297 \\
\hline HPV-35 & $21 \quad(6.1)$ & $6(5.0)$ & $9 \quad(7.8)$ & $6(5.3)$ & 0.54 \\
\hline HPV-33 & $19 \quad(5.5)$ & $6(5.0)$ & $6 \quad(5.2)$ & $8(7.1)$ & 0.732 \\
\hline HPV-31 & $14 \quad(4.0)$ & $6(5.0)$ & $4(3.5)$ & $4 \quad(3.5)$ & 0.683 \\
\hline HPV-45 & $12(3.5)$ & $5(4.2)$ & $6 \quad(5.2)$ & $1 \quad(0.9)$ & 0.151 \\
\hline Single-type infection & $262(75.5)$ & $91(76.5)$ & $92(80.0)$ & $79(69.9)$ & 0.167 \\
\hline Multiple-type infection & $85(24.5)$ & $28(23.5)$ & $23(20.0)$ & $34(30.1)$ & 0.226 \\
\hline
\end{tabular}

Table 4 - Demographic and clinical features of inpatients infected with different human papilloma virus (HPVs).

\begin{tabular}{|c|c|c|c|c|c|c|}
\hline Demographic and clinical features & $\begin{array}{c}\text { HPV-16 } \\
(\mathrm{n}=86)\end{array}$ & $\begin{array}{c}\text { HPV-18 } \\
(\mathrm{n}=40)\end{array}$ & $\begin{array}{c}\text { HPV-52 } \\
(\mathrm{n}=59)\end{array}$ & $\begin{array}{c}\text { HPV-68 } \\
(\mathrm{n}=57)\end{array}$ & $\begin{array}{c}\text { Other HPV } \\
(\mathrm{n}=149)\end{array}$ & $P$-value \\
\hline Median age (years) & 43 & 32.5 & 40 & 40 & 43 & 0.041 \\
\hline Range (years) & $33-50.5$ & $25-47$ & $33-48.5$ & $31-51$ & $31-50$ & \\
\hline Ethnic, $n(\%)$ & & & & & & 0.635 \\
\hline Han & $70(81.4)$ & $34(85.0)$ & $52(88.1)$ & $51(89.5)$ & $130(87.2)$ & \\
\hline Others & $16(18.6)$ & $6(15.0)$ & $7(11.9)$ & $6(10.5)$ & $19(12.8)$ & \\
\hline $\begin{array}{l}\text { Age during first sexual encounter } \\
\text { Median age (range) }\end{array}$ & $\begin{array}{c}22 \\
(20-23)\end{array}$ & $\begin{array}{c}21 \\
(20-22)\end{array}$ & $\begin{array}{c}21 \\
(20-22)\end{array}$ & $\begin{array}{c}21 \\
(20-22)\end{array}$ & $\begin{array}{c}22 \\
(20-23)\end{array}$ & 0.148 \\
\hline Smoking, $n(\%)$ & & & & & & 0.029 \\
\hline Yes & $12(14.0)$ & $3(7.5)$ & $2(3.4)$ & $7(12.3)$ & $6(4.0)$ & \\
\hline No & $74(86.0)$ & $37(92.5)$ & $57(96.6)$ & $50(87.7)$ & $143(96.0)$ & \\
\hline Pregnancy, $n$ (\%) & & & & & & $<0.001$ \\
\hline Single & $9(10.5)$ & $9(22.5)$ & $12(20.3)$ & $12(21.1)$ & $54(36.2)$ & \\
\hline Multiple & $70(81.4)$ & $29(72.5)$ & $41(69.5)$ & $44(77.2)$ & $68(45.6)$ & \\
\hline Abortion, $n(\%)$ & & & & & & 0.476 \\
\hline Yes & $55(64.0)$ & $19(47.5)$ & $36(61.0)$ & $34(59.6)$ & $93(62.4)$ & \\
\hline No & $31(36.0)$ & $21(52.5)$ & $23(39.0)$ & $23(40.4)$ & $56(37.6)$ & \\
\hline
\end{tabular}


patients with cervical lesions in cities or provinces in China. ${ }^{10-14}$ The present findings provide information on HPV prevalence and genotype distributions in Zunyi City, Guizhou Province, China.

The overall HPV prevalence rate in Zunyi was $15.1 \%$, which is similar to the previously reported rates of $13.3-18.4 \%$ in other cities or provinces in China ${ }^{10,11,15,16}$ The prevalence of HPV in this study.was lower than those reported in other regions, such as Japan $(31.7 \%),{ }^{17}$ Iran $(45.4 \%),{ }^{18}$ and Africa $(22.1 \%),{ }^{19}$ but higher than those in Vietnam (9.5\%), ${ }^{20}$ Europe (8.1\%), and North America (11.3\%). ${ }^{19}$ Differences in the prevalence might partially be attributed to differences in the sample population, socioeconomic environment, and lifestyle. In Zunyi region, the number of cases and prevalence rates of HPV infection continuously increased from 2014 to 2016, which may partly be explained by the improvement in economy, a change in lifestyle, and the availability of HPV screening in some parts of this region.

HPV-16, HPV-18, HPV-52, and HPV-58 have been widely known as the major prevalent genotypes in most regions, ${ }^{5}$ and HPV-68 was rarely ranked among the top five. However, in this study, HPV-68 was ranked the second most prevalent genotype in Zunyi, China. In addition, HPV-68, HPV-16, and HPV-52 were the top 3 genotypes found in inpatients with multiple-type HPV infection in Zunyi (Table 2), whereas HPV-16, HPV-52, and HPV-58 were the top 3 genotypes found in multiple-type infection in Yunnan and Guangdong provinces, China; ${ }^{10,21} \mathrm{HPV}-16, \mathrm{HPV}-31$, and HPV-58 in Cyprus; ${ }^{22}$ and HPV-16, HPV-45, and HPV-6 in Iran. ${ }^{18}$ Through careful examination of the HPV genotypes in cervical lesions, HPV-16 and HPV-68 were the top 2 most prevalent genotypes in population with $\mathrm{CINs}$ and $\mathrm{CC}$, and their incidences increased as the severity of lesions increased (Table 1). In this study, the number of CC cases was small; however, all of them were confirmed to have multiple infections, and five were co-infected with genotypes HPV-68, and HPV-16. Therefore, this finding confirmed that HPV-16 and HPV-68 were the major genotypes contributing to CINs and CC in this region. This evidence further support the concept that co-infection with multiple HPV genotypes may have an have additive effect in cervical carcinogenesis. ${ }^{23,24}$

Age has been associated with the prevalence of HPV genotypes. ${ }^{17}$ In this study, HPV-18 appeared to be more prevalent in persons younger than 35 years, whereas HPV-59, HPV-56, and HPV-51 were more prevalent in persons aged $>46$ years. Nevertheless, its cause remains unclear. Another important finding was the frequent occurrence of $\mathrm{CC}$ in persons aged $>46$ years. This may partially be attributed to the poor eradication ability of HPV virus in old people. In addition, HPV infection was also found to be associated with smoking, confirming the previous evidence that smoking is a risk factor for CC development. ${ }^{25}$ Another important risk factor was pregnancy, and women with multiple pregnancies tended to be infected with high-risk genotypes of HPV-16 and HPV-68 (Table 4). Therefore, we may conclude that age, smoking history, and pregnancy may be important determinants for infection with high-risk HPV genotypes.

Based on our literature review, this is the first report to evaluate the prevalence and distribution of HPV genotypes in non-vaccinated women from Zunyi, China. Cervarix was introduced in China in 2016, but only includes genotypes HPV-16 and HPV-18. Based on our finding, this vaccine only covers a limited percentage of HPV genotypes (35.4\%) circulating in this region, and does not cover the high-risk HPV-68. Thus, a novel HPV vaccine including high-risk genotypes should be introduced in this region.

This study has some limitations. First, only a limited number of high-risk HPV genotypes were detected, which may influence the estimation of HPV prevalence. Second, genotypes 6 and 11 were not determined, which affected the estimation of the coverage rate for Gardasil 9. Third, only a small proportion of cases from other ethnic groups were enrolled, which may affect in some degree the generalizability of the findings. Finally, the number of inpatients was small; therefore, more participants are necessary to make a precise conclusion.

In conclusion, this study shows that HPV-16, HPV-52, HPV-68, and HPV-58 are the most prevalent genotypes in non-vaccinated women in Zunyi, China, and HPV-16 and HPV-68 are the main genotypes associated with cervical pre-cancer and cancer lesions; these genotypes are suggested to be included in a novel HPV vaccine.

Acknowledgment. This study was supported by research grants from Innovation talent team of Science and Technology jointly provided by Zunyi City and the First People's Hospital of Zunyi, the special fund for Science and Technology Cooperation between Guizhou Province and Zunyi City, and Projects of the National Natural Science Foundation of China.

\section{References}

1. Chen W, Zheng R, Baade PD, Zhang S, Zeng H, Bray F, et al. Cancer statistics in China, 2015. CA: Cancer J Clin 2016; 66: 115-132.

2. World Health Organization. Human papillomavirus (HPV) and cervical cancer. [Update 2018; Accessed 2018 May 25]. Available at: http://www.who.int/en/news-room/fact-sheets/ detail/human-papillomavirus-(hpv)-and-cervical-cancer 
3. Smith JS, Lindsay L, Hoots B, Keys J, Franceschi S, Winer $\mathrm{R}$, et al. Human papillomavirus type distribution in invasive cervical cancer and high-grade cervical lesions: A meta-analysis update. Int J Cancer 2007; 121: 621-632.

4. Clifford GM, Smith JS, Plummer M, Mu-oz N, Franceschi S. Human papillomavirus types in invasive cervical cancer worldwide: a meta-analysis. Br J Cancer 2003; 88: 63-73.

5. Castellsagué X, de Sanjosé S, Aguado KS, HPV WIICo, C. C. HPV and cervical cancer in the 2007 report. Vaccine 2007; 25(Suppl 3): C1-C230.

6. Liu SS, Chan KYK, Leung RCY, Chan KKL, Tam KF, Luk MHM, et al. Prevalence and risk factors of human papillomavirus (HPV) infection in Southern Chinese women. A population-based study. PloS One 2011; 6: e19244.

7. Daily C. China approves use of GSK vaccine Cervarix for cervical cancer. [Update 2016; Accessed 2017 Deceber 21]. Available from: http://www.chinadaily.com.cn/business/201607/19/content_26141434.htm

8. Kurman RJ, Norris HJ, EJ W. Tumors of the Cervix, Vagina, and Vulva. Washington (DC): Armed Forces Institute of Pathology; 1992.

9. Bruni L, Diaz M, Castellsagué X, Ferrer E, Bosch FX, de Sanjosé S. Cervical human papillomavirus prevalence in 5 continents: meta-analysis of 1 million women with normal cytological findings. J Infect Dis 2010; 202: 1789-1799.

10. Baloch Z, Li Y, Yuan T, Feng Y, Liu Y, Tai W, et al. Epidemiologic characterization of human papillomavirus (HPV) infection in various regions of Yunnan Province of China. BMC Infect Dis 2016; 16: 228.

11. Wu R-f, Dai M, Qiao Y-l, Clifford GM, Liu Z-h, Arslan A, et al. Human papillomavirus infection in women in Shenzhen City, People's Republic of China, a population typical of recent Chinese urbanisation. Int J Cancer 2007; 121: 1306-1311.

12. Zhang Y, Wang Y, Liu L, Guo C, Liu Z, Nie S. Prevalence of human papillomavirus infection and genotyping for population-based cervical screening in developed regions in China. Oncotarget 2016; 7: 62411-62424.

13. Jin Q, Shen K, Li H, Zhou X-r, Huang H-f, Leng J-h. Agespecific prevalence of human papillomavirus by grade of cervical cytology in Tibetan women. Chin Med J (Engl) 2010; 123: 2004-2011.

14. Tang Y, Zheng L, Yang S, Li B, Su H, Zhang L. Epidemiology and genotype distribution of human papillomavirus (HPV) in Southwest China: a cross-sectional five years study in nonvaccinated women. Virol J 2017; 14: 84.
15. Dai M, Bao YP, Li N, Clifford GM, Vaccarella S, Snijders PJF, et al. Human papillomavirus infection in Shanxi Province, People's Republic of China: a population-based study. $\mathrm{Br} J$ Cancer 2006; 95: 96-101.

16. Ye J, Cheng X, Chen X, Ye F, Lü W, Xie X. Prevalence and risk profile of cervical human papillomavirus infection in Zhejiang Province, southeast China: a population-based study. Virol J 2010; 7: 66.

17. Takehara K, Toda T, Nishimura T, Sakane J, Kawakami Y, Mizunoe T, et al. Human papillomavirus types 52 and 58 are prevalent in uterine cervical squamous lesions from Japanese women. Path Res Int 2011; 2011: 1-7.

18. Salehi-Vaziri M, Sadeghi F, Hashemi FS, Haeri H, BokharaeiSalim F, Monavari SH, et al. Distribution of human papillomavirus genotypes in Iranian women according to the severity of the cervical lesion. Iran Red Crescent Med J 2016; 18: e24458.

19. de Sanjosé S, Diaz M, Castellsagué X, Clifford G, Bruni L, Munoz N, et al. Worldwide prevalence and genotype distribution of cervical human papillomavirus DNA in women with normal cytology: a meta-analysis. Lancet Infect Dis 2007; 7: 7.

20. Van SN, Khac MN, Dimberg J, Matussek A, Henningsson AJ. Prevalence of cervical infection and genotype distribution of human papilloma virus among females in Da Nang, Vietnam. Anticancer Res 2017; 37: 1243-1247.

21. Jing L, Zhong X, Zhong Z, Huang W, Liu Y, Yang G, et al. Prevalence of human papillomavirus infection in Guangdong Province, China. Sex Transm Dis 2014; 41: 732-738.

22. Krashias G, Koptides D, Christodoulou C. HPV prevalence and type distribution in Cypriot women with cervical cytological abnormalities. BMC Inf Dis 2017; 17: 346.

23. Trottier H. Human papillomavirus infections with multiple types and risk of cervical neoplasia. Cancer Epidemiol Biomark Preven 2006; 15: 1274-1280.

24. Woodman CBJ, Collins S, Winter H, Bailey A, Ellis J, Prior $P$, et al. Natural history of cervical human papillomavirus infection in young women: a longitudinal cohort study. Lancet 2001; 357: 1831-1836.

25. Appleby P, Beral V, Berrington de Gonzalez A, Colin D, Franceschi S, Goodill A, et al. Carcinoma of the cervix and tobacco smoking: collaborative reanalysis of individual data on 13,541 women with carcinoma of the cervix and 23,017 women without carcinoma of the cervix from 23 epidemiological studies. Int J Cancer 2006; 118: 1481-1495. 